\title{
A mudança da carreira dos dirigentes após o processo de privatização: estudo de caso no setor elétrico paulista
}

\section{The change of leader's career after the privatization process: a case study in São Paulo electricity sector}

\author{
Patricia Mari Matsuda ${ }^{1}$ \\ Julio Cesar Donadone ${ }^{1}$
}

\begin{abstract}
Resumo: Esta pesquisa investiga como uma companhia muda após o processo de privatização, e como esta mudança acaba por influenciar sua total estrutura. Para tanto, o escopo desta pesquisa se concentrou em um estudo exploratório na AES Eletropaulo. A importância central do estudo no setor elétrico brasileiro é que esse setor tem sido sujeito a transformações mais radicais na financeirização desde 1990. No entanto, nenhuma pesquisa sobre as carreiras construídas de dirigentes nesse contexto brasileiro tem sido feita até agora. Como procedimento de pesquisa deste trabalho, combinaram-se os métodos quantitativo e qualitativo. A fim de analisar a carreira dos dirigentes da AES Eletropaulo, foram coletados os currículos do Conselho Administrativo e da Diretoria, desde o seu surgimento como empresa estatal em 1979, até o ano de 2012. Foi aplicada uma análise de correspondência múltipla para estudar esses currículos. Além disso, para complementar a pesquisa, foi realizada uma entrevista com o ex-presidente da empresa estudada. Como resultado, foi possível observar uma série de transformações que a AES Eletropaulo sofreu, principalmente que os dirigentes dessa empresa tiveram que buscar formas de reconstruir suas carreiras de acordo com a nova lógica do momento, voltada para financeira.
\end{abstract}

Palavras-chave: Privatização; Estrutura organizacional; SPSS; Finanças

\begin{abstract}
This research investigates how a company changes after the privatization process and how this change impacts its total structure. Therefore, this research focused on an exploratory study at AES Eletropaulo. This study has a central role in the Brazilian electricity sector because due t the radical changes it's been subjected since 1190's financialization. However, no research on careers construction of leaders in the Brazilian context had been made so far. As a research procedure this studycombined quantitative and qualitative methods in order to analyze the careers of leaders of AES Eletropaulo, we collected the curriculum of the Board and Directors, since its emergence as a state enterprise in 1979 to the year 2012. These curriculums were analyzed with a multiple correspondence analysis. In addition, this research was complemented with an interview with the former president of the company were the study was performed. As a result, we were able to observe of the several changes that AES Eletropaulo went through, especially that, the leaders of this company had to find ways to rebuild their careers according to the new logic of the moment, which would have been facing financial.
\end{abstract}

Keywords: Privatization; Organizational structure; SPSS; Finance.

\section{Introdução}

Desde a década de 1990, as maiores empresas do mundo têm passado por um processo contínuo de transformações. Segundo Donadone \& Sznelwar (2004, p. 59), nos Estados Unidos “[...] enfatiza-se o processo pelo qual o entendimento e as representações acerca do mundo organizacional foram sendo colonizadas pela lógica financeira." Nesse período ocorre a "mudança na Governança Corporativa com a atuação de grandes investidores institucionais, representados por fundos de pensão, companhias de seguro e fundos de investimento". A escolha dos Estados Unidos, pelos referidos estudiosos, dá-se, pois, ele se apresenta como "principal polo de influência e desenvolvimento histórico do setor, sede das maiores empresas líderes e o maior mercado mundial".

De acordo com Donadone \& Sznelwar (2004, p. 60), no Brasil a dinâmica organizacional coloca em destaque o processo de privatizações como um dos principais

\footnotetext{
${ }^{1}$ Departamento de Pós-graduação em Engenharia de Produção, Universidade Federal de São Carlos - UFSCar, São Carlos, SP, Brasil, e-mail: patrícia.ufscar@hotmail.com; donadojc@uol.com.br
}

Recebido em Fev. 18, 2015 - Aceito em Abr. 08, 2015

Suporte financeiro: CAPES. 
acontecimentos dos anos 1990: "A transferência para setores privados de grandes empresas estatais foi um importante fator de mudança nos arranjos organizacionais do período."

As privatizações fazem surgir um novo modelo de empresa, denominado Modelo 2 por Grün (1999, 2003). O autor explica que, enquanto o modelo 1 se refere a gerentes e engenheiros, o Modelo 2, aos especialistas da área financeira. Para ele, o processo de privatização, nos anos 1990 aumenta drasticamente a relevância do Modelo 2 no Brasil. "A razão financeira aparece como uma espécie de denominador comum que fornece um índice mínimo compartilhado das formas de entender e, consequentemente, de agir sobre as empresas." (Grün, 1999, p. 129).

Associados às privatizações, ocorreram os processos de fusões e aquisições. Nesse movimento, a concepção que tem sido dominante nas grandes firmas é a financeira. Com essa nova reorganização, passam a existir os novos donos. Para Donadone \& Sznelwar (2004, p. 60), “[...] as pressões dos novos donos das empresas têm consequência no desenho organizacional e na composição do poder nas empresas."

As companhias brasileiras estatais têm sido sujeitas às transformações desde a década de 1990. Esse fator foi impulsionado quando as companhias de energia elétrica participaram do processo de privatização do governo (Pedroso, 2005).

Este presente trabalho tem como objetivo central analisar, em uma empresa deste setor, em âmbito corporativo, as (novas) formas de gestão organizacional e da produção, como também seus atores-chaves e suas formas de inter-relação. Para tanto, o escopo de pesquisa se concentrou em um estudo exploratório na AES Eletropaulo, empresa de distribuição de energia do setor elétrico paulista. Com o foco voltado para a análise das carreiras dos dirigentes da companhia, antes e pós-privatização (AES Eletropaulo, 2012; AES Brasil, 2013)

Este trabalho vai contribuir para o estudo de uma grande empresa brasileira, que tem suas particularidades de cultura e formação (Hirsch et al, 1990). Relatar sobre a formação da mais importante empresa de distribuição do país, de forma a investigar aspectos ligados à formação de dirigentes no contexto histórico da empresa no momento antes, durante e pós-privatização. A presente pesquisa é relevante, pois existem poucos estudos realizados em grandes empresas brasileiras, e o que se tem, segundo os autores Bethlem (2014) e Lazzarini (2011), são traduções de casos de grandes empresas estrangeiras.

\section{Metodologia}

Para o desenvolvimento deste trabalho, o foco é na análise das carreiras dos dirigentes da companhia. Seria um estudo para verificar quem são os agentes do processo de mudança da companhia. Objetiva-se nesta análise verificar como são construídas e reconstruídas as carreiras dos dirigentes da AES Eletropaulo após as grandes transformações.

Nesta pesquisa, utilizou-se a Análise de Correspondência Múltipla-ACM, pois a príncipío se verificou a presença de engenheiros no corpo dirigente da AES Eletropaulo. Por isso, como se trata uma empresa que sofreu transformações e caminhou para a financeirização, o fato de haver engenheiros antes e depois da privatização é um dado relevante, pois investigou-se se o engenheiro antes da privatização que está no corpo dirigente é o mesmo do período pós-privatização.

$\mathrm{O}$ nome dado, nesta pesquisa, ao engenheiro a ser analisado será o Tipo I (antes da privatização), e o Tipo II (depois da privatização). Espera-se na ACM verificar se esses Tipos são os mesmos. Primeiramente, já se sabe que temos engenheiros no corpo dirigente da companhia AES Eletropaulo, antes e depois. Porém, o que se espera na Análise de Correspondência Múltipla é associar essa variável a outras para formar os Tipos I e II.

Esses Tipos I e II devem possuir características interconectadas, referentes ao período antes acumulado e depois acumulado, características que formam um conjunto. Busca-se descobrir quais os atributos dominantes dos engenheiros, explicar se são engenheiros de diferentes Tipos e ainda considerar que temos dois grupos diferentes a serem analisados: o Diretor e o Conselheiro Administrativo, cada qual com suas definidas funções dentro da organização.

Dessa análise, o objetivo é mostrar que existe um conjunto de variáveis relacionadas ao Tipo I e um conjunto de variáveis relacionadas ao Tipo II. E que mesmo ambos sendo engenheiros, carregam outras variáveis associadas que permitem dizer que são Tipos diferentes de engenheiros, em diferentes momentos da empresa.

A escolha em analisar o CA e a Diretoria deveu-se ao conceito dado, segundo Bethlem (2014), de que a empresa tem na sua direção duas funções principais: a função proprietário e a função dirigente. A função proprietário na empresa AES Eletropaulo é exercida pelos acionistas, pois pela dificuldade de se reunir os acionistas criou-se o Conselho da Administração. Já a função dirigente executa as determinações da função proprietário, que no caso da AES Eletropaulo são os Diretores.

A metodologia utilizada para entender quem são os Tipos I e II foi a combinação de dois métodos: quantitativo e qualitativo. Para a análise quantitativa, utilizou-se a ferramenta estatística ACM, e para a qualitativa, utilizou-se a ferramenta entrevista. 


\subsection{Técnica de análise de dados: Método quantitativo - Análise de Correspondência Múltipla - ACM}

Para o levantamento de quem são os agentes da empresa, foram feitas análises estatísticas, para a análise do currículo de seus dirigentes, desde o seu surgimento como empresa estatal em 1979 até o ano de 2012.

As informações de currículos dos Conselheiros Administrativos e Diretoria do ano de 2012 foram retiradas do site institucional da empresa AES Eletropaulo. Na seção "Relação com Investidores", foi possível ter acesso ao currículo resumido do atual CA e Diretoria. Documentos referentes aos anos entre 1998 e 2008 foram retirados da biblioteca da AES Eletropaulo, da Fundação Patrimônio Histórico da Energia e Saneamento e, principalmente, de dados da Comissão de Valores Mobiliários - CVM (2012). As informações dos anos entre 1993 e 1997 ainda não estavam digitalizadas, porém arquivadas na CVM, por isso foi necessária uma visita à empresa. Os nomes de CA e Diretoria 1983 a 1986 da AES Eletropaulo foram coletados nos relatórios anuais da Fundação Patrimônio Histórico da Energia e Saneamento.

Como nos relatórios do período de 1983 a 1986 só havia nomes de Conselheiros e Diretoria, mas não seus minicurrículos, os pesquisadores recorreram a sites de busca na internet. Os que são professores foram mais fáceis de encontrar, porque apareciam nos sites da Universidade de São Paulo (USP) e na Plataforma Lattes. A dificuldade com os demais se deveu ao fato de que, no referido período, diversos dados estão incompletos ou difíceis de encontrar, devido à falta do uso da tecnologia da informação. Sendo assim, a leitura dos currículos nesse intervalo de tempo foi feita com algumas lacunas (Fundação Patrimônio Histórico da Energia e Saneamento, 2012).

Quando a companhia foi estatizada, com a compra da companhia Light S.A., ficou dois anos sob o domínio do Governo Federal. Desse modo, seus dois primeiros presidentes foram os mesmos da Eletrobrás, como pode ser observado no Dicionário Biográfico do Setor de Energia Elétrica Brasileiro (Correa \& Carneiro, 2002).

Dentre as variáveis selecionadas para a análise dos currículos, foram criadas categorias: Universidade de graduação (exterior, estadual, particular, federal, IBMEC/GV); Formação da graduação (engenharia, direito, economia, administração etc.); Universidade de pós-graduação (exterior, estadual, particular, federal, IBMEC/GV, não tem); Formação de pós-graduação (engenharia, direito, economia, administração, não tem); Passado profissional (governo, grupo AES, outros 1 - empresas, outros 2 - sindicato, acadêmico e outros, financeiro, setor elétrico).

Como amostra desta pesquisa, foram analisados 56 Conselheiros e 21 Diretores, sendo esse o corpo dirigente do período antes da privatização (1993 a 1996). E, de 1998 a 2012, foram analisados 226 Conselheiros e 85 Diretores, ou seja, dirigentes do período pós-privatização.

\subsection{Técnica de análise de dados: Método qualitativo - Entrevistas}

Para o estudo da empresa, de toda a sua história, desde sua criação até os dias de hoje, foi utilizada a ferramenta qualitativa entrevista. A entrevista foi realizada em 8 de agosto de 2014, com Eduardo Bernini (2014), ex-presidente da AES Eletropaulo. Ele preparou a companhia para privatização (96-98) e voltou à presidência da companhia em 2003-2007, quando costurou o acordo junto com o BNDES para formação da Brasiliana, holding que agrega o BNDES e o grupo americano AES. A entrevista foi realizada em 08 de agosto de 2014.

\section{Desenvolvimento}

A operacionalização da ACM teve a validação de dados pelo grupo de estatística EJE - Empresa Júnior de Planejamento \& Consultoria, vinculada ao Departamento de Estatística - DEs da Universidade Federal de São Carlos - UFSCar.

Muitas vezes ao analisar conjuntamente variáveis categóricas e verificar a relação entre elas, não e é possível observar numericamente as respostas. Para isso, utilizam-se tabelas de contingência, na qual se organizam os números de ocorrências simultâneas das categorias de todas as características em estudo (Roux \& Rouanet, 2010).

A situação usual de análise é verificar a existência ou não de associação das variáveis em estudo, considerando as combinações duas a duas através da estatística Qui-Quadrado de Pearson, a equação utilizada é dada por (Equação 1):

$$
\sum_{i=1}^{p} \sum_{j=1}^{p} \frac{\left(o_{i j}-e_{i j}\right)^{2}}{e_{i j}}
$$

Dessa forma, os valores dos desvios em relação à hipótese de independência são estudados, verificando a existência ou não de associação das características. Sabe-se que, quando são independentes, não existe relação entre elas, porém, quando há associação, o conhecimento de uma das características implica a ocorrência de determinados valores na outra com maior ou menor probabilidade.

A Análise de Correspondências é um procedimento exploratório multivariado para o estudo das tabelas de contingência, nas quais é possível observar essas relações. Quando existem apenas duas variáveis em estudo, a Análise de Correspondência é Simples, enquanto, para o caso de mais variáveis, ela é Múltipla. Tal análise, por suas propriedades estatísticas e 
riqueza de interpretações, tornou-se um método muito utilizado na descrição de dados categóricos. Seus dois grandes objetivos são:

- Analisar toda a informação contida em uma tabela de contingência.

- Representar graficamente a estrutura desta tabela.

Os dados em uma pesquisa normalmente são obtidos por um questionário, neste caso foi coletado em minicurrículos. Os pesquisadores têm uma listapadrão de categorias mutuamente exclusivas. Assim, os investigadores podem associar a cada uma delas um código, para que possa facilitar a interpretação dos resultados, como foi aplicado nesta pesquisa.

No caso da ACM, torna-se inviável a construção de uma tabela de contingência, devido à impossibilidade de "cruzar" todas as características observadas, sendo necessário buscar alternativas como a Tabela Lógica e a Tabela de Burt.

A Tabela de Burt resume a informação através de uma tabela simétrica que apresenta o conjunto das tabelas de contingência que podem ser construídas cruzando, duas a duas, as características observadas. Assim, ela apresenta:

- Na intersecção da j-ésima linha com a j-ésima coluna, o valor indica o número de indivíduos que apresentam a j-ésima modalidade de uma dada característica;

- Na intersecção da j-ésima linha com a k-ésima coluna, o valor é igual a zero se a j-ésima modalidade e a k-ésima modalidade pertencem a uma mesma característica;

- Na intersecção da q-ésima linha com a k-ésima coluna, o valor indica o número de indivíduos que apresentaram, simultaneamente, a q-ésima modalidade de uma característica e a q-ésima modalidade de outra característica.

A distância é calculada da seguinte forma - observe a Equação 2 dada abaixo:

$$
\begin{aligned}
d^{2}\left(\mathrm{j} ; \mathrm{j}^{\prime}\right)= & \sum_{k=1}^{k}\left[\sqrt{\frac{n}{p}}\left(\frac{n_{j k}}{n_{j \cdot \sqrt{n_{k}}}}\right)-\sqrt{\frac{n}{p}}\left(\frac{n_{j^{\prime} k}}{n_{j^{\prime}} \sqrt{n_{k}}}\right)\right] 2 \\
& =\frac{1}{p} \sum_{k=1}^{k} \frac{n}{n_{k}}\left(\frac{n_{j k}}{n_{j}}-\frac{n_{j^{\prime} k}}{n_{j^{\prime}}}\right) 2
\end{aligned}
$$

Após o cálculo das distâncias, nota-se que duas modalidades de uma mesma variável estarão obrigatoriamente distantes no espaço de representação, duas modalidades comuns à maioria dos indivíduos observados estarão representadas pelo mesmo ponto no espaço de representação. Já modalidades com baixa frequência estarão bastante afastadas das demais.
Portanto, a partir da Análise de Correspondência Múltipla, é possível estudar todos os indivíduos em questão, com base no conjunto de todas as variáveis, as relações entre todas as modalidades das variáveis observadas e resumir o conjunto de variáveis em um pequeno conjunto de novas variáveis quantitativas relacionadas ao conjunto de todas as variáveis em estudo.

Outro aspecto importante é a contribuição da inércia (variabilidade) de uma modalidade e a inércia total dos pontos. Ela é dada pela Equação 3 a seguir:

$$
\operatorname{Contrib}(j)_{I_{G_{M}}}=\frac{1}{p} \times\left(1-\frac{n_{j}}{n}\right)
$$

Como consequência disso, verifica-se que quanto mais rara é uma modalidade, maior é sua contribuição para a inércia total da nuvem de pontos-modalidade. Assim, essa categoria estará isolada, dificultando a interpretação das demais. Pode-se observar também que a inércia total será dada pela Equação 4, apresentada a seguir:

$$
I_{G_{M}}=\sum_{j=1}^{k} \operatorname{Contrib}(j)_{I_{G_{M}}}=\sum_{j=1}^{k}\left(\frac{1}{p} \times\left(1-\frac{n_{j}}{n}\right)\right)=\frac{K}{p}-1
$$

Ou seja, a inércia total é um valor fixo e depende unicamente do número de variáveis observadas e do número de modalidades definidas para essas variáveis.

Para definição do número de eixos a serem utilizados para a análise, uma alternativa geralmente utilizada é analisar a estrutura de decrescimento dos autovalores. Nesse caso,7 devem ser investigados os eixos cujos autovalores não se enquadram na forma "regular" de decrescimento dos autovalores.

O software utilizado para realizar a ACM foi o Statistical Analysis Software - SAS, que seria mais apropriado para flexibilidades quanto à programação. Também foi usado o software Statistical Package for the Social Sciences - SPSS, pois ele apresenta uma facilidade de criação de dados e gráficos de forma prática. Sendo o resultado gráfico analisado de forma subjetiva pelos pesquisadores. Lembrando que os resultados obtidos devem ser os mesmos, independentemente dos softwares utilizados. Esta seção prepara os dados para a ACM que será realizada posteriormente.

Na Tabela 1 a seguir são apresentadas as variáveis e as categorias criadas para análise dos currículos do Conselho e Diretoria da AES Eletropaulo. Visando uma melhor apresentação gráfica, foi elaborada uma legenda para as possíveis respostas de cada variável.

\subsection{Período pré-privatização}

Para ter certa noção do perfil acadêmico e profissional dos Conselheiros e Diretores da AES Eletropaulo de 1993 até 1996, uma análise descritiva foi realizada, 
Tabela 1. Legenda das variáveis.

\begin{tabular}{|c|c|c|}
\hline Variável & Respostas & Legenda \\
\hline \multirow[t]{5}{*}{ Universidade da Graduação } & Exterior & G1 \\
\hline & Estadual & G2 \\
\hline & Particular & G3 \\
\hline & Federal & G4 \\
\hline & IBMEC/FGV & G5 \\
\hline \multirow[t]{5}{*}{ Formação da Graduação } & Engenharia & GF1 \\
\hline & Direito & GF2 \\
\hline & Economia & GF3 \\
\hline & Outros & GF4 \\
\hline & Administração & GF5 \\
\hline \multirow[t]{6}{*}{ Universidade da Pós-Graduação } & Exterior & PG1 \\
\hline & Estadual & PG2 \\
\hline & Particular & PG3 \\
\hline & Federal & PG4 \\
\hline & IBMEC/FGV & PG5 \\
\hline & Não Tem & PG6 \\
\hline \multirow[t]{6}{*}{ Formação da Pós-Graduação } & Engenharia & PGF1 \\
\hline & Direito & PGF2 \\
\hline & Economia & PGF3 \\
\hline & Outros & PGF4 \\
\hline & Administração & PGF5 \\
\hline & Não Tem & PGF6 \\
\hline \multirow[t]{6}{*}{ Passado Profissional } & Governo & PP1 \\
\hline & Grupo AES & PP2 \\
\hline & Outros 1 (Empresas) & PP3 \\
\hline & Outros 2 (Sindicatos, Acadêmico, outros) & PP4 \\
\hline & Financeiro & PP5 \\
\hline & Setor Elétrico & PP6 \\
\hline
\end{tabular}

Fonte: Elaborada pelos autores.

separando os cargos de acordo com suas duas possíveis opções. Foram analisados 56 Conselheiros e 21 Diretores.

A Figura 1 mostra, graficamente, o resultado da Análise de Correspondência representando as duas dimensões.

Ao considerar as categorias agrupadas da Figura 1, é possível inferir que: Diretores tendiam a terem feito a graduação em Universidades Estaduais no curso de Engenharia, assim como o curso de pós. O passado profissional se dava no setor elétrico ou em sindicatos, academia (GF1, PGF1, PP4, G2 e PP6). Conselheiros tendiam a terem feito a graduação em Universidades Particulares, pós no Exterior e passado profissional em áreas do Governo (G3, PP1 e PG1).

\subsection{Período pós-privatização}

Para ter certa noção do perfil acadêmico e profissional de Conselheiros e Diretores da AES Eletropaulo de 1998 até 2012, a pesquisa realizou uma análise descritiva separando os cargos de acordo com suas duas possíveis opções. Foram analisados 226 Conselheiros e 85 Diretores. A seguir, o gráfico obtido através da Análise de Correspondência representando as duas dimensões.

Dessa forma, pela Figura 2, é possível identificar as categorias agrupadas, e assim infere-se que:

- Diretores tendiam a terem feito a graduação em Engenharia e Direito, a pós em Universidades do Exterior ou Estaduais e o passado profissional no setor financeiro (GF1, GF2, PG1, PG2, PP5).

- Conselheiros tendiam a terem feito a graduação em Universidades Particulares no curso de Economia, assim como o curso da pós. O passado profissional no setor elétrico ou em outras empresas (G3, GF3, PGF3, PP3, PP6). 


\section{Revisão de literatura - Estudo sobre a carreira do engenheiro e sua reconversão na empresa caso AES Eletropaulo}

Neste tópico, os resultados obtidos da ACM são organizados no tema "engenheiro reconvertido". Trata-se de uma discussão sobre a principal carreira do corpo de dirigentes da empresa AES Eletropaulo na atualidade. Nessa ocasião, discute-se a reconversão de carreira de seus dirigentes, conforme as mudanças na estrutura da empresa.

De acordo com os resultados da ACM, Diretores antes da privatização tendiam a terem feito a graduação em Universidades Estaduais no curso de Engenharia, assim como o curso de pós-graduação na mesma área, e o passado profissional no setor elétrico ou em sindicatos e academia (GF1, PGF1, PP4, G2 e PP6).

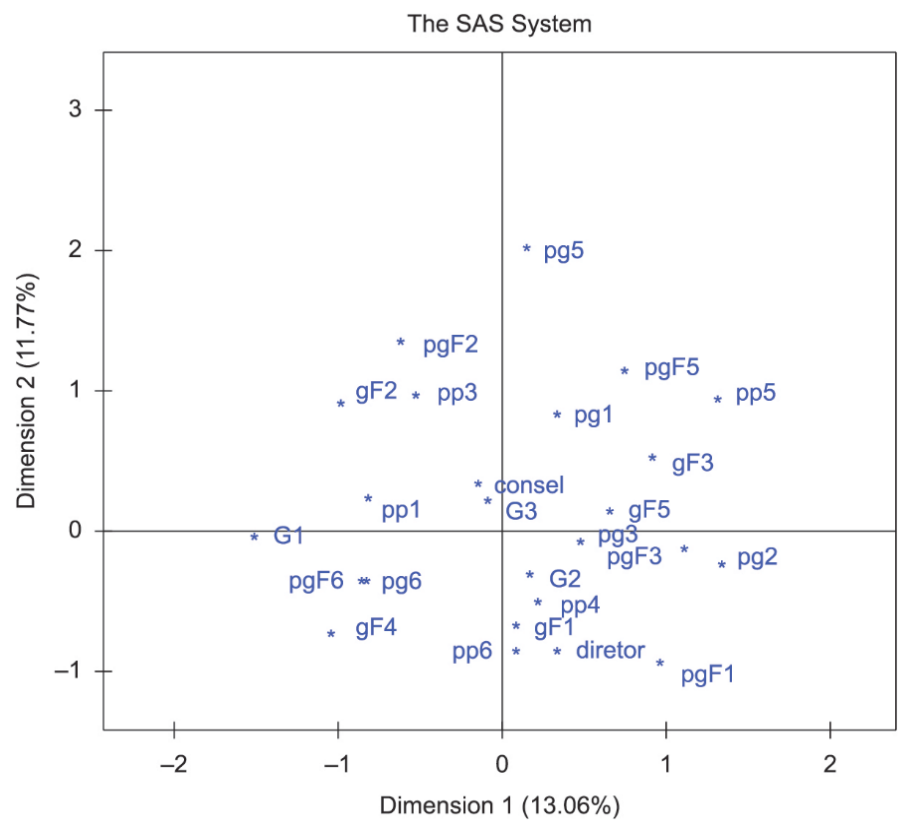

Figura 1. Gráfico da Análise de Correspondência sem as categorias PG4, G5 e G4 - período pré-privatização. Fonte: Elaborado pelos autores.

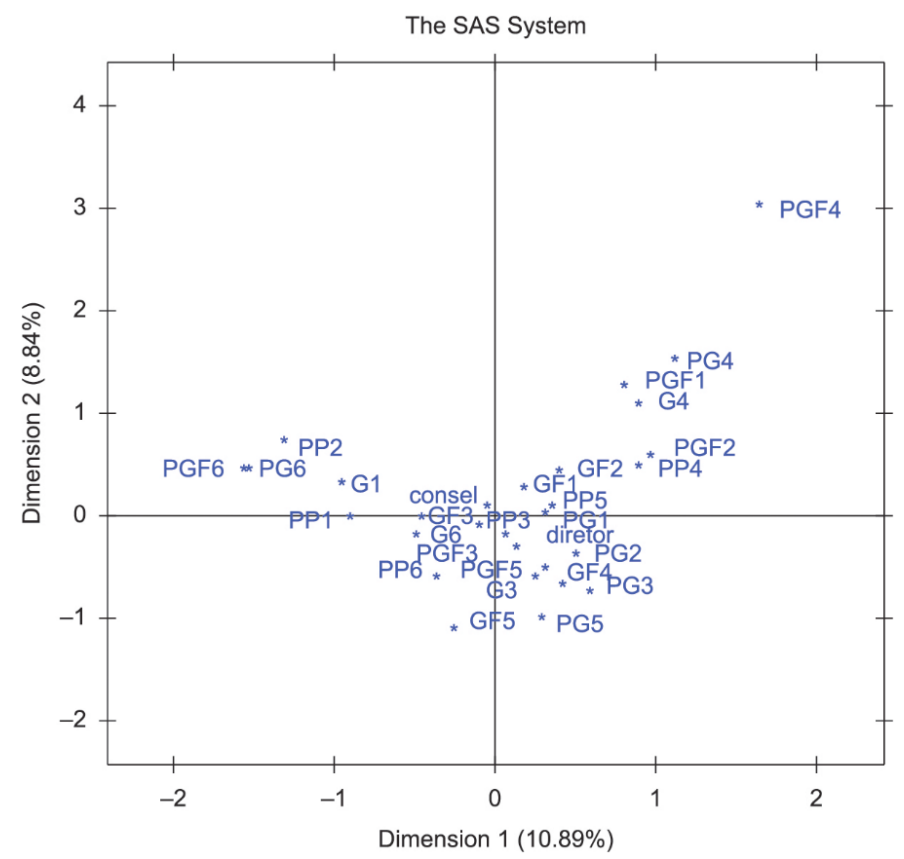

Figura 2. Gráfico da Análise de Correspondência - período pós-privatização. Fonte: Elaborado pelos autores. 
Já no período depois da privatização, os Diretores tendiam a terem feito a graduação em Engenharia e Direito, a pós-graduação em Universidades do Exterior ou Estaduais e o passado profissional no setor financeiro (GF1, GF2, PG1, PG2, PP5).

Na presente seção, a missão é explicar essa trajetória do Diretor - denominada nesta pesquisa de "engenheiro reconvertido". Para isso, inicia-se a discussão em: (1) discussão da formação do engenheiro na história do ensino no Brasil e no mundo, com destaques para o período do fordismo e pós-fordismo; (2) atuação e qualificação do engenheiro a partir das mudanças no cenário sócio-político-econômico; (3) através da entrevista com Eduardo Bernini, apresenta-se como esse engenheiro cria sua trajetória em momentos diferentes da mesma empresa; (4) e considerações finais sobre este tema.

\subsection{Formação do engenheiro a partir da história do ensino no Brasil e no mundo - destaques ao período fordista e pós-fordista}

Sobre o histórico das escolas de engenharia, Bruno \& Laudares (2000) observam que a primeira escola de engenharia foi a École des Ponts et Chaussées, criada na França em 1775. Nessa fase, a formação do engenheiro era voltada para a construção civil. Vinte anos mais tarde foi criada, em 1798, a École Polytechnique.

Na Europa, nos Estados Unidos e também no Brasil, as primeiras escolas de engenharia datam no começo do século XIX, pois a prática do engenheiro se realizava na sociedade política. "Tanto a formação como o trabalho estavam ligados à arte militar, sua tecnologia funcionava como meio de segurança e repressão." (Bruno \& Laudares, 2000, p. 492).

Os autores comentam que a relação educativa dos países está estritamente ligada ao tipo do regime de produção. Na primeira Revolução Industrial, os esforços foram para capacitar mais mão de obra. Assim, expandiu-se o trabalho do engenheiro para suprir esta demanda. Já no século XX, com a administração científica, e separação de tarefas, surgiram-se especialidades da engenharia.

Nos anos 1980, com a crise do fordismo, ocorreu a "[...] desregulamentação do trabalho, acompanhando movimento de flexibilidade dos sistemas de produção. Tais mudanças afetaram a base da formação profissional, principalmente dos engenheiros." (Bruno \& Laudares, 2000, p. 493).

Nesse momento de passagem do fordismo para o pós-fordismo, houve mudanças nas fábricas quanto às exigências e qualificações do engenheiro. $\mathrm{O}$ engenheiro a partir desse contexto ocupa posição estratégica de "[...] gerenciamento de pessoas e processos que exigem recursos humanos e sociais somados àqueles de cunho puramente técnico [...]" (Bruno \& Laudares, 2000, p. 492)

Com a terceira Revolução Industrial, no Brasil nos anos 1990, e com o salto no desenvolvimento da microeletrônica e da indústria de informática, a nova ordem mundial se traduz pela integração mundializada. Até recentemente, engenheiros exerciam atividades técnicas. Atualmente, com a mudança na organização das empresas e o aumento da terceirização e redução dos trabalhadores, inclusive engenheiros, "[...] suas atribuições foram ampliadas e tornaram-se mais diversificadas, inclusive com conhecimentos administrativas, comerciais e gerenciais, de liderança e de estrutura de custos [...]" (Bruno \& Laudares, 2000, p. 495).

Segundo os estudiosos, o capital já não é mais industrial, mas financeiro e comercial. Na medida em que várias formas de organização entram em colapso, elas se diferenciam dos períodos anteriores, seja no interior de processo de trabalho, onde o fordismo dá lugar à acumulação flexível, seja no político econômico, das relações capitalistas, com a criação da fábrica global e de empresas multinacionais (Silva, 2004).

Nessa passagem da privatização e desregulamentação, novas relações de trabalho são desenvolvidas. Desse modo, o trabalho do engenheiro exige dele competências diferentes do período industrial anterior. A formação acadêmica do engenheiro

certamente não mais se faz somente em áreas de exatas, sua requalificação no serviço requer novos saberes, com as relações sociais originadas da posição flexível, em face das demandas da abertura de processos de trabalho.

Por ocuparem posições de destaque nas fábricas e serem agentes multiplicadores e difusores de processos, torna-se necessária a inserção dos engenheiros em programas de educação continuada, de conteúdo administrativo, geral e humanístico, que complementem sua formação técnica e possibilitem uma melhor elaboração dos conhecimentos adquiridos na prática.

Para Bruno \& Laudares (2000), o engenheiro precisa ter memória histórica, para transferência e aplicabilidade do conhecimento. Sua requalificação se faz pelos novos processos de organização e gestão de trabalho, que trazem, além da exigência técnica, habilidades de administração da produção, comportamento e interação originalizada pela descentralização produtiva, presente nos atuais modelos de gestão (Zilbovicius, 1999).

\subsection{Atuação e qualificação do engenheiro a partir das mudanças ocorridas no cenário sócio-político-econômico}

Após a breve história da construção do curso de engenharia no Brasil e no mundo, destacam-se algumas transformações pelas quais esse profissional passou, 
devido às alterações no cenário sócio-político-econômico no qual ele se insere. Em poucas palavras, trata-se da mudança do modelo 1 de empresa, industrial, para o modelo 2 de empresa, financeiro. Em meados da década de 1990, há um novo enfoque da empresa que serve para contemplar os interesses dos acionistas: o movimento de financeirização. A partir dessa mudança, novas formas de organização do trabalho se desenvolvem e altera-se a atuação do engenheiro.

Segundo Martins (2014) e Crivellari (2000), as mudanças ocorridas nas empresas no período de transição entre o fordismo e pós-fordismo foram concomitantes à transformação do capitalismo produtivo para o capitalismo financeiro. Tais mudanças nas organizações tiveram impacto sobre as carreiras dos dirigentes, nesse caso, os engenheiros.

De acordo com Martins (2014), com a crise fordista ocorreu a queda na produtividade do trabalho, perda de competitividade econômica e a solução foi a política neoliberal, com a redução da participação do Estado nas empresas como tentativa de solucionar essa crise.

Crivellari (2000, p. 27) explica que, se no passado o Estado formava engenheiros para a grande indústria estatal, hoje, na era pós-fordista, a política do Estado mínimo é caracterizada pela privatização da indústria. Essa nova estrutura empresarial "[...] vai resultar em outra relação de forças que pode demandar em uma relação educativa, entre os atores envolvidos na política de produção industrial, e formação de mão de-obra."

Com a nova lógica socioeconômica que surge, "[...] se a sua capacidade de trabalho é a mercadoria que tem que vender, num mercado altamente competitivo, impõe-se que a mercadoria ganhe atrativos diferenciados para ganhar espaço no mercado [...]" (Silva \& Cecílio, 2007, p. 75). Cunha (2000) complementa que se deve considerar que o mercado vai demandar dos engenheiros uma série de habilidades e competências, lembrando que agora o objetivo da empresa é o lucro e a sobrevivência no mercado.

Esse momento histórico, consoante Grün (1999), é importante para a transformação e reestruturação do capitalismo produtivo, que por sua vez redireciona algumas carreiras e profissões. Com cortes de funções e o processo de terceirização de um grande contingente de dirigentes, engenheiros são movidos de seus antigos empregos. É dentro desse processo de mudanças organizacionais que se pode ver uma forte mudança em planos de carreira e inserção profissional de vários agentes ligados ao contexto de negócios, como é o caso dos engenheiros reconvertidos.

\subsection{Engenheiro reconvertido da AES Eletropaulo}

Jardim (2011) se apoia em dois autores franceses para explicar o conceito de reconversão, aplicando-o ao caso brasileiro. Assim, estudando o interesse de sindicalistas brasileiros (especialmente da CUT) por previdência complementar, a autora defende a passagem das tradicionais estratégias de lutas para "novas estratégias sindicais", compreendidas como a gestão de fundos de pensão no mercado financeiro. $\mathrm{O}$ "movimento" dos sindicalistas em direção ao mercado financeiro é denominado por Jardim de reconversão, ou seja, uma mudança que pressupõe não somente alteração no espaço social, mas sobretudo alteração cognitiva, de hexis corporal, de linguagem, simbólica, de novos aliados e novas alianças, etc. Portanto, considerando seu campo empírico (gestão sindical de fundos de pensão), a autora afirma que "[...] a reconversão é a chave para interpretar os mecanismos de mudança social, ou, ao contrário, a ausência de mudança [...]", sendo que "[...] reclassificação significa o resultado da reconversão de sucesso [...]". Dessa forma, em se tratando do percurso da reconversão, reclassificação e desclassificação são dois termos opostos entre si. Jardim finaliza: “[...] as lutas de classificação (e de reclassificação) são fundamentais para definir as condições sociais [...]" (Jardim, 2011, p. 8).

Com inspiração na argumentação de Jardim, indicamos que os engenheiros da AES Eletropaulo fazem a reconversão em direção ao mercado financeiro, a qual legitima e justifica a manutenção de cargos de posição de elite. Apesar da carência em formação administrativa, os engenheiros buscam a legitimidade por meio de pós-graduações nas áreas de business, tendo em vista as novas exigências administrativas para lidar com os stakeholders da empresa, no período pós-privatização, voltada ao mercado financeiro.

Pensando na AES Eletropaulo, há a exemplificação do cenário de uma empresa que passa pelo movimento de financeirização e incorpora precisamente os referidos engenheiros-reconvertidos. Através da análise do currículo dos dirigentes (CA e Diretoria) da AES Eletropaulo, desde o seu surgimento como uma empresa estatal em 1979 até o ano de 2012, percebe-se a reconversão da carreira de seus engenheiros.

$\mathrm{Na}$ entrevista de Eduardo Bernini, ele relata que a AES Eletropaulo é uma empresa de engenharia. O entrevistado diz que os engenheiros, após a privatização, precisam adquirir capacitações mais diversificadas pelo alto grau de exposição da empresa ao mercado, referida pelas regras de Governança Corporativa. Eduardo Bernini diz:

[...] com a pós-privatização ela continua sendo uma empresa de engenharia, mas cujo perfil profissional, pelas demandas da nova estrutura de regulação em que esse negócio opera, passou a exigir um conjunto de capacitações mais diversificadas. E a última camada de diversificação de competências foi quando obviamente passou a ser uma empresa com alto grau de exposição ao mercado e precisou ser regida pelas regras da governança corporativa 
Eduardo Bernini fala sobre a trajetória do atual presidente da Eletropaulo, Britaldo Soares:

O Britaldo saiu da Faculdade de Minas, se formou em Belo Horizonte diretamente para o Citibank, para o programa de trainee do Citibank, e nunca mais na vida ele saiu do setor financeiro. E você vai encontrar certas evidências nos currículos dos brasileiros, em que os engenheiros viram suco no dia em que se formam. Eles deixam de ser engenheiros e vão ser administradores financeiros ou vão ser gestores [...]. As estratégias hoje têm evidentemente o condicionante de como atender a esses múltiplos interesses dos stakeholders.

Eduardo Bernini em sua entrevista afirma: “[...] você tem uma engenharia financeira, uma engenharia regulatória, que são engenharias entre aspas", e ele complementa, "onde você tem hoje a necessidade de profissionais muito especializados na regulação e não generalistas, muitos profissionais especializados na estruturação financeira desse negócio, que tem inclusive particularidades muito grandes". O ex-presidente esclarece a necessidade de maiores especializações, a fim de atender as necessidades de negociações da empresa com o público e o privado.

Sobre a posição dos Conselheiros, o ex-presidente da AES Eletropaulo afirma ter Conselheiros de diferentes tipos dentro da empresa: independentes, internos e externos, exigidos pelo nível 2 de Governança Corporativa, no qual a empresa AES Eletropaulo se encontra.

Nesse sentido, é interessante observar a constatação de Bethlem (2014, p. 32) sobre a existência de três tipos de Conselheiros: os independentes "[...] sem ligação pessoal ou profissional com a empresa e seus dirigentes"; externos "Conselheiros que não têm vínculo atual com a sociedade, mas são independentes [...]"; e os Conselheiros internos, "[...] que são Diretores e funcionários da empresa [...]". Voltando ao posicionamento de Eduardo Bernini:

Conselheiros internos são Conselheiros que são indicados pelo controlador e que exercem algum tipo de atividade profissional vinculada ao controlador. Ou são Diretores de outras empresas, ou são Diretores da controladora, ou são Diretores da holding, mas essencialmente são assalariados na ativa que são indicados para compor Conselhos da Administração de controladas ou de participadas.

O Conselheiro externo é o Conselheiro que em algum momento de sua vida profissional teve algum vínculo empregatício ou contratual com o controlador, então ele pode ter sido um ex-Diretor, um advogado externo ou um consultor que teve algum tipo de vínculo contratual com o controlador, então ele não é um Conselheiro independente. O Conselheiro interno é um profissional que tem vínculo empregatício ou contratual com o controlador hoje o externo pode não ter esse vínculo contratual empregatício, mas o teve em passado recente.
E o Conselheiro independente, que é por exclusão, é aquele que não teve nenhum tipo de vínculo anterior com o grupo controlador e nem com a companhia e pelas regras do Novo Mercado, de governança do Novo Mercado, as companhias com esse nível têm que ter no mínimo $20 \%$ do seu Conselho composto por um independente.

Para a forma com que foram analisados os currículos dos Conselheiros da AES Eletropaulo, e como os resultados foram agrupados, esta nova forma de governança é um dado relevante. Ainda, o ex-presidente explica que, no período antes das privatizações, a indicação para o CA era pautada numa política de relacionamentos: "Na pré-privatização, a indicação era disfuncional, ela era evidentemente de natureza política de relacionamentos, e era um conselho honorífico, embora tivesse todas as responsabilidades que as leis das S.A. preveem para o Conselho de Administração".

Já no período pós-privatização, ele diz que havia mais transparência de escolha de CAs, motivadas pelas regras de GC do Nível 2 da Bovespa: "Hoje, para atender o Nível 2 da Bovespa, e o fato de a Eletropaulo ter $52 \%$ do seu capital pulverizado na bolsa, hoje você tem uma composição de Conselheiros independentes. Se não me engano são quatro Conselheiros independentes, que se enquadrariam dentro dessa categorização."

Pensando nos resultados da ACM sobre as caracterizações dos Conselheiros antes da privatização, já expostos, e nas classificações dadas por Eduardo Bernini, fica mais fácil entender o porquê das diferenças de passado profissional do CA. Antes da privatização, eram ocupados por profissionais que construíram seu passado profissional no Governo, ou seja, a indicação, citada pelo ex-presidente, ocorria por laços políticos; já no período depois da privatização, pela maior transparência na empresa de capital aberto, e pertencente ao Nível 2 de GC, com a existência de CA independente, interno e externo, surgem os Conselheiros que tiveram passado profissional em outras empresas e no mesmo setor.

\section{Considerações finais sobre o engenheiro reconvertido}

Inspirando-nos no conceito de reconversão dado por Jardim (2011), o engenheiro reconvertido da empresa caso busca formas de se manter em posições de elite, adquirindo pós-graduações na área de business, de acordo com as novas necessidades da empresa, que antes era industrial e hoje financeira, isto é, voltada para o interesse dos acionistas. Os engenheiros acabam tendo que se comunicar com diferentes áreas da companhia e responder, segundo o ex-presidente Eduardo Bernini, a contratos públicos e privados, e atender aos interesses de diversos stakeholders do 
novo ambiente em que a companhia está inserida. $\mathrm{O}$ engenheiro reconvertido é a figura que se legitima e se mantém no cargo no período pós-privatização.

Diversos autores destacam essa mudança na carreira do engenheiro de acordo com o cenário sócio-político-econômico. Eles mostram que houve mudanças nas empresas no período do fordismo para o pós-fordismo, culminando no mesmo período a transformação nas empresas de um capitalismo produtivo para um capitalismo financeiro. E que essas modificações acabaram por impactar sobre as carreiras dos dirigentes, nesse caso, os engenheiros.

A relação educativa está ligada ao tipo de produção. No período fordista, os esforços estavam focados nas especialidades da engenharia. Já nos anos 1980, com a crise do fordismo, mudanças ocorreram na formação do profissional de engenharia: houve a exigência de conhecimentos sociais, pois suas habilidades deveriam ser ampliadas para outras áreas e não as de cunho somente técnico. Ademais, tiveram que adquirir conhecimentos em áreas comerciais, gerenciais, administrativas, de custo e liderança. Foi a mudança do capital industrial para o comercial e financeiro, conforme Martins (2014) e Crivellari (2000).

Eduardo Bernini disse que, após a privatização, os engenheiros precisavam adquirir capacitações mais diversificadas, pelo alto grau de exposição da empresa ao mercado, refletida pelas regras de GC. Ele fala em sua entrevista sobre o atual presidente da AES Eletropaulo, Britaldo Soares, que atua como profissional da área financeira e já trabalhou como Chief Financial Officer-CFO (Diretor Financeiro no Brasil) antes de a empresa ter uma área de relacionamento com investidores. Essa necessidade surgiu a partir da reorganização do setor e exigiu um novo tipo de profissional com especialidades de administração para gerir aos diversos stakeholders da cadeia.

Já sobre o papel do CA, o ex-presidente falou da necessidade de Conselheiros internos, externos e independentes, devido à exigência do Nível 2 de GC. Ele ressalta que, antes da privatização, a indicação para o CA era pautada numa política de relacionamentos, e a indicação feita de forma disfuncional.

Diante do exposto, percebe-se que os engenheiros acumulam novos capitais - sociais, educacionais, culturais, por exemplo - necessários para atender as mudanças da empresa. E esta reconversão dos engenheiros para o mercado financeiro, através das buscas em áreas administrativas, é uma forma de demonstrar entendimento e adaptação dessa classe às mudanças na sociedade e suas classificações e reclassificações.

\section{Resultados}

Como resultado, foi possível observar uma série de transformações na empresa AES Eletropaulo no período pós-privatização. Especialmente os seus dirigentes, analisados nesta pesquisa, tiveram que criar caminhos para reconstruir suas carreiras, de acordo com a nova lógica predominante do momento, voltada para o foco financeiro.

Como foi levantado no início desta pesquisa, existia a presença de engenheiros no corpo dirigente da AES Eletropaulo, e com o processo de financeirização da economia, (Froud et al., 2006), procurou-se verificar se esses engenheiros são os mesmos, por se tratar de uma empresa que foi privatizada e, como consequência, passou pelo processo de financeirização.

Por fim, chega-se à conclusão de que a capacidade de reconversão é muito grande nessa empresas que os engenheiros acabam por reconverter suas carreiras. A análise apresenta dados com períodos acumulados antes e pós-privatização por meio da Análise de Correspondência Múltipla.

Com essa análise, aplicada no período de 1993 a 1996, foi possível uma identificação de grupos em que os Diretores tendem a ter suas características explicadas por terem estudado em escolas estaduais, engenharia com experiência no setor elétrico, sindicato e academia. Já no período pós-privatização (1998 a 2010), os Diretores tendem a ter suas características explicadas pelo estudo em universidade estadual, no exterior, em engenharia ou direito, e pela carreira construída no setor financeiro.

Os Conselheiros tendem, antes da privatização, a ter suas características explicadas pelo estudo em escola particular, no exterior, e trabalhado para o governo. Ao passo que, após privatização, a característica dos Conselheiros é o estudo em universidade particular, cursos de economia, pós em economia e atuação profissional no setor elétrico e em outras empresas.

A reconversão do engenheiro na empresa caso AES Eletropaulo é definida por uma nova estratégia de atuação em nível internacional do grupo AES Corporation, ao qual a AES Eletropaulo pertence. A condução dos negócios pelo grupo consiste em uma política de financeirização constante.

$\mathrm{Na}$ transformação de movimentos produtivos em movimentos financeiros (Fligstein, 1990; Useem, 1999), a AES Eletropaulo reduz a hierarquia gerencial eliminando funções de supervisão. Essas mudanças no trabalho atribuem remodelação dos cargos dos engenheiros associados a essa unidade produtiva pesquisada.

De acordo com Martins (2014), com o corte das funções e com os processos de terceirizações, um contingente de grandes dirigentes, os engenheiros, é deslocado de seus possíveis empregos. Assim, é possível trabalhar com a ideia de isomorfismo profissional ou isomorfismo normativo, usando a nomenclatura de DiMaggio \& Powell (1983). Conforme o autor, o mecanismo no qual as profissões e ocupações são sujeitas à coerção e pressão mimética de outras organizações é chamado de isomorfismo. Martins 
(2014, p. 146) usa esse conceito para explicar a adesão e a proliferação de condutas profissionais na área financeira por atores sociais, e ressalta que esse isomorfismo pode ser de dois modos: pela educação formal e pelo crescimento da rede entre profissionais (Scott, 1995).

Mais ainda, Martins (2014, p. 147) afirma que "[...] as elites financeiras controlam o sistema social através de seu comando e posicionamento frente às organizações.” E, dessa forma, “[...] criam e recriam cerimônias e mitos que podem dirigir condutas profissionais em benefício de seus interesses [...]". Para a autora, os dirigentes que foram excluídos dos seus espaços sociais usaram a legitimação financeira para posteriormente trabalhar para o capitalismo financeiro.

A primeira constatação é que Diretores da AES Eletropaulo, em sua maioria, possuem graduação em Engenharia. Este tipo de profissão sofreu transformações ao longo dos anos após o processo de financeirização. Consoante Martins (2014), como resultado dessas transformações, em relação ao mercado de trabalho, observam-se mudanças na formação escolar de Conselheiros e Diretores, e a tendência à internacionalização da formação em área de negócios e finanças como meio de manutenção da carreira e de status profissional.

No que diz respeito à profissão, tanto antes como depois do processo de privatização, entre os Conselheiros e Diretores, a profissão que se destaca é a Engenharia. O processo de internacionalização também é destacado através das pós-graduações dos indivíduos estudados. Após a privatização, há uma abertura para cursos realizados no exterior e também em institutos nacionais voltados para gestão administrativa e financeira.

Segundo Martins (2014), é somente no período de 1950 que iniciou no Brasil a atividade profissional dos economistas. Logo, a partir de 1960, há um crescimento do número de ingressos das faculdades de economia que sobrepõe o número de ingressos das faculdades de engenharia e direito. Os cursos de pós-graduação em economia são criados a partir da década de 1970. No entanto, a ocupação maciça de cargos estratégicos da burocracia por parte dos economistas se dá significativamente a partir da segunda metade dos anos 1980.

Martins (2014) e Gomes (1994), comentam que a cristalização tardia dos cursos de economia, e o fato de a atividade profissional ter se consolidado a partir dos anos 1950, podem ser sidos um dos motivos pelos quais era a engenharia a primeira profissão a se consolidar com intuito de formar e moldar as primeiras elites brasileiras.

O peso desse tipo de formação repercute na presente análise, uma vez que a empresa possui um número substancial de engenheiros nos cargos até os dias atuais. Sendo uma empresa de distribuição de energia, sempre vai precisar de engenheiros para entender o processo.

Desse modo, de acordo com Martins (2014), nota-se ainda uma predileção pela contratação de engenheiros dentro das empresas brasileiras, mesmo depois de uma possível abertura para os cursos de economia e management no país.

Conforme a autora, no mundo atual, as empresas e os indivíduos se financeirizam, mas, ao mesmo tempo, há no Brasil a repetição de traços do passado, que marcam a mistura entre o tradicional e o moderno, a qual continua a destacar uma profissão que fazia parte do tripé das profissões hierárquicas no país desde o Império até hoje.

O novo profissional, apresentado por estudos na AES Eletropaulo, segue a linha do novo trabalhador de elite, com Diretores que estudaram no exterior e em áreas financeiras. A figura do engenheiro se manteve, como explicado anteriormente, por ser uma profissão de elite que, ao longo dos anos, remodelou sua carreira, e por sua necessidade em uma empresa de fornecimento de energia. Por fim, os Conselheiros trocaram de empresa, ou seja, trabalharam em outras empresas antes para chegarem ao topo.

De acordo com Martins (2014), Medicina, Direito e Engenharia são as carreiras de elite no Brasil desde os primórdios. Todavia, a Engenharia se vê diante da necessidade de sua inserção em outras áreas consideradas de menor importância tradicionalmente.

A palavra reconversão para o engenheiro surge na primeira vez coincidindo com os períodos de transição do fordismo para o pós-fordismo, que ocorre concomitantemente com a mudança de empresa industrial para empresa financeira. Esses trabalhadores se atualizam através de cursos e pós-graduações, adquirem novas habilidades nas áreas humanas, administrativas e sociais, para se tornarem mais flexíveis em um primeiro momento de mudança organizacional e se reconvertem em engenheiros que trabalham em áreas financeiras num segundo momento, para poderem se manter nas suas posições de elite. Tudo isso marcado e explicado pela preferência de contratação de engenheiros nas grandes empresas brasileiras para cargos de alto escalão.

\section{Agradecimentos}

Agradecemos à instituição CAPES pelo suporte financeiro.

\section{Referências}

AES Eletropaulo (2012). Estatuto. Recuperado em 05 de abril de 2012, de http://ri.aeseletropaulo.com.br/ Show.aspx?id_canal=WbeL5yMj5AURIjvKkI7MsQ ==\&id_materia=fpcN9TY4TA11S+5aupPjcQ== 
AES Brasil (2013). Histórico no Brasil. Recuperado em 25 de abril de 2013, de http://www.aesbrasil.com.br/ ogrupo/Paginas/historiconobrasil.aspx

Bernini, E. (2014). AES Eletropaulo (Entrevista a Patricia Mari Matsuda). São Paulo: Tempo Giusto Consultoria Empresaria.

Bethlem, A. (2014). Direção estratégica de empresas brasileiras. Rio de Janeiro: Elsevier.

Bruno, L. B., \& Laudares, J. B. (Orgs.). (2000). Trabalho e formação do engenheiro. Belo Horizonte: Fumarc.

Comissão de Valores Mobiliários - CVM (2012). Currículos da AES Eletropaulo. São Paulo.

Correa, M. L., \& Carneiro, A. D. (2002). Dicionário biográfico do setor de energia elétrica brasileiro. Rio de Janeiro: Centro da Memória da Eletricidade no Brasil.

Crivellari, H. (2000). Relação educativa e formação de engenheiros em Minas Gerais. In L. B. Bruno \& J. B. Laudares (Orgs.), Trabalho e formação do engenheiro (pp. 227-267). Belo Horizonte: Fumarc.

Cunha, F. M. (2000). A formação do engenheiro na área humana e social. In L. B. Bruno \& J. B. Laudares (Orgs.). Trabalho e formação do engenheiro (pp. 267312). Belo Horizonte: Fumarc.

Dimaggio, P. J., \& Powell, W. W. (1983). The iron cage revisited: institutional isomorphism and colletive rationality in organizations fields. American Sociological Review, 48(2), 147-160. http://dx.doi. org/10.2307/2095101.

Donadone, J. C., \& Sznelwar, L. I. (2004). Dinâmica organizacional, crescimento das consultorias e mudanças nos conteúdos gerenciais nos anos 90. Production, 14(2), 58-69. http://dx.doi.org/10.1590/S010365132004000200006.

Fligstein, N. (1990). The transformation of corporate control. Cambridge: Harvard University Press.

Froud, J., Johal, S., Leaver, A., \& Williams, K. (2006). Financialization \& strategy: narrative and numbers. Routledge: Oxford.

Fundação Patrimônio Histórico da Energia e Saneamento (2012). Currículos da AES Eletropaulo. São Paulo.

Gomes, A. (1994). Engenheiros e economistas: a nova elite burocrática. Rio de Janeiro: Editora FGV.
Grün, R. (2003). Atores e ações na construção da governança corporativa brasileira. Revista Brasileira de Ciencias Sociais, 18(52), 121-143. http://dx.doi. org/10.1590/S0102-69092003000200008.

Grün, R. (1999). Modelos de empresa, modelos de mundo: sobre algumas características culturais da nova ordem econômica e da resistência a ela. Revista Brasileira de Ciências Sociais, 14(41), 121-140.

Hirsch, P., Michaels, S., \& Friedman, R. (1990). Clean models vs. dirty hands: why economics is different from sociology. In Z. Sharon \& P. Di Maggio (Eds.), Structures of capital: the social organization of the economy (pp. 39-56). New York: Cambridge.

Jardim, M. A. C. (2011). Presença de centrais e sindicatos no mercado financeiro: criação e gestão de fundos de pensão. Estudos de Sociologia, 16(31), 20-30.

Lazzarini, S. G. (2011). Capitalismo de laços: os donos do Brasil e suas conexões. Rio de Janeiro: Elesevier.

Martins, T. J. (2014). A nova elite financeira no Brasil: Jogos, estratégias e disputas entre os - gerentes-engenheiros e os acionistas. Revista de Economia Política e História Econômica, 10, 116-149.

Pedroso, N. A. J. (2005). A privatização do setor elétrico paulista: suicídio de um grupo (Tese de doutorado), Universidade Federal de São Carlos, São Carlos.

Roux, B. L., \& Rouanet, H. (2010). Multiple correspondence analysis (Quantitative application in the social science). Thousand Oaks: SAGE Publications.

Scott, W. R. (1995). Institutions and organizations. London: Gafe Publications.

Silva, C., \& Cecílio, S. (2007). A mudança no modelo de ensino e a formação de engenharia. Educação em Revista, 45, 61-80.

Silva, E. B. (2004). Pós-fordismo no Brasil. Revue d'Economie Politique, 14(3), 107-120.

Useem, M. (1999). Investor capitalism: how money mangers are changing the face of corporate America. New York: Basic books.

Zilbovicius, M. (1999). Modelos para a produção, produção de modelos: gênese, lógica e difusão do modelo japonês de organização da produção. São Paulo: Editora FAPESP/AnnaBlume. 